\title{
Risks Assessment Expending AHP-GA Method: A Novel Approach for Hazard Factors of Barapukuria Coal Mine in Bangladesh.Risks Assessment Expending AHP-GA Method: A Novel Approach for Hazard Factors of Barapukuria Coal Mine in Bangladesh.
}

Kawsar Ahmed ( $\nabla$ kahmedstats@gmail.com )

Central South University

Md. Zahidul Islam

Central South University

Md. Nuralam Hossain

Chongqing University

Hongwei Deng

Central South University

Research Article

Keywords: AHP-GA Method, Coal Mine, Hazard Factors, MCDM, Mine Safety, Bangladesh

Posted Date: May 10th, 2021

DOI: https://doi.org/10.21203/rs.3.rs-509599/v1

License: (c) (i) This work is licensed under a Creative Commons Attribution 4.0 International License.

Read Full License 


\title{
Risks Assessment Expending AHP-GA Method: A Novel Approach for Hazard Factors of Barapukuria Coal Mine in Bangladesh.
}

\author{
Kawsar Ahmed $^{1}$ Md. Zahidul Islam² $・$ Md. Nuralam Hossain ${ }^{3}$ Hongwei Deng ${ }^{2}$
}

\begin{abstract}
Mining industry's working milieu is influenced by various hazardous factors. Perhaps in Bangladesh, future working environments will be insecure for the lack of congenial methodology to reduce risk factors of Barapukuria Coal Mine (BCM). Many inconsistencies were found in multi-criteria judgment and resolution problems in mine. The study objective is to amplify with Analytic Hierarchy Process (AHP)-Genetic Algorithm (GA) method for solving accidental factors identifying problems in the BCM field. Our promised tactics is for risk appraisement at BCM. We are wary of the methodology for risk factors to identify and secure a thriving way for working with better ambience in mining by including year wise accidental data from 2002 to 2012. Our evaluation framework was described with a widespread three layer that analyzed step by step by Microsoft excel and MATLAB software. The weight value and accuracy of the assigned matrix was calculated for the mentioned AHP-GA method. To enhance efficiency, this paper pretends to resolve a multi-decisional puzzle with intimate connection of AHP-GA from the advantage of MCDM, and minimizes the gap of combining GA with AHP for practical application. AHP-GA technique will perform in a fruitful way both on qualitative and quantitative multi-assessment complex solutions in coal mines. In this study, we have elaborated the application of AHP-GA procedure which surrounds the value to enlarge the better decision local option on mining areas for BCM. Finally, we come into view the BCM safety level is inclined to "General" by our proposed novel setting.
\end{abstract}

Keywords: AHP-GA Method, Coal Mine, Hazard Factors, MCDM, Mine Safety, Bangladesh

$\triangle \quad$ Kawsar Ahmed

Kahmedstats@gmail.com

Md. Zahidul Islam

zahidulislam.pme@gmail.com

Md. Nuralam Hossain

nuralam.05mbstu@gmail.com

Hongwei Deng

denghw208@126.com

1 School of Mathematics and Statistics, Central South University, Hunan, 410075, China

2. School of Resources \& Safety Engineering, Central South University, Hunan, 410075, China

3 School of Environment and Ecology, Chongqing University, Chongqing, 400045, China

4 School of Resources \& Safety Engineering, Central South University, Hunan, 410075, China

\section{Introduction}

Risk assessment is a systematic way of identifying and analyzing the hazard associated with mining activities. Proper safety managements save miners and increase production, so pay close attention is first and foremost maintaining a friendly working environment in mine. Hazards cannot be eliminated, but there is a need to define and estimate a possible accident causes to be presented either quantitatively or qualitatively [3]. Now, Barapukuria Coal Mine (BCM) is the only active coal mine in Bangladesh [26]. Many dangerous factors exist in the BCM, such as poisonous gases, coal dust, roof fall, fire explosion, electrical, mechanical, water inrush, side fall, spontaneous combustion, and so forth. Besides, employee's health can be endangered by the high temperature humidity in mining areas [2]. The reason of the accidents is nearly different due to various working conditions and ambience in underground. Since, factors are related to trigger accidents, safety 
assessment in coal mining is particularly important [29]. In the meantime, coal mine safety assessment methods are used in many pathways to achieve better judgment. Positively, Multiple-criteria decisionmaking (MCDM) approaches may be used to outrank alternatives or make a final decision based on the objective [28]. In everyday life and a variety of industries, MCDM methods are used to solve problems involving selection, classification, and sorting. Many methods such as AHP, AAP, ELECTRE, PROMETHEE, TOPSIS, VIKOR, SAW, and GIA applied for safety assessment [11]. AHP systematic evaluation methods were used in different countries around the world to determine the safety of coal mines. It decomposes the assessment system into some levels, including target level, standard level, and scheme level [23]. A major characteristic of AHP is the hierarchical formulation of parameters, which was first introduced by Miller in his Ph.D. thesis in 1966 [7]. Due to its basic mathematical expressions, AHP is convenient and simple for experts to render multi-criteria decisions. AHP can easily and quickly operate both quantitative and qualitative parameters. Users may also adjust the priority rating values to perform a risk assessment. While AHP is well-known as one of the best MCDM methods, it has been used effectively in a variety of fields [4]. For example, recent studies have shown the Fuzzy AHP's positive effectiveness and easy to use. The assessment results are accurate and provide a decision basis for the coal miner's safety output [15-18]. In previous methods application, there is an ambiguity to choose proper methods except for available data, and using inappropriate methods may flourish an erroneous evaluation result [11]. As a result, applying MCDM to check for a novel calculation has become a desire to achieve the optimal result we need. However, our proposed AHP-GA method can mitigate this form of challenge and close the gap between using MCDM to evaluate other mining risk management approaches in this study. Practical application to mine, roof collapse is the most serious threat in the Tabas Coal Mine in Iran, according to the proposed procedure [13-14]. Using a coal mine in Anhui Province is another example of application. Furthermore, the use of fuzzy logic to evaluate human behavior allows for early detection of potentially hazardous work system evolutions and alerts those in control in underground coal mining [19-20]. Relying on quality function deployment (QFD), fuzzy inference scheme(FIS) and AHP, all possible hazards and implications is applied in workplace system evaluating for mining companies [21].

In addition, the GA is a novel search method for practical applications that focuses on the process of evolution. John Holland [34], invented it in the early 1970s. GA is a useful method for determining the best selection of judgment evaluation criteria. It is possible to solve a variety of optimization problems by applying a genetic algorithm in which the optimization problem is irregular, non-differentiable, random, or strongly non-linear. A genetic algorithm (GA) was used as the significance degree to solve the accuracy of decision matrix and calculate the index weighting factors [23]. It is combining the analytical theory application of the genetic algorithm (GA) and Analytic Hierarchy Process (AHP) that is "AHP-GA" method. It will be fruitful compared to other MCDM approaches in the coal mine. In the present work the AHP-GA approach is used to assess the protection for the coal mine safety with the weight value solution method. To the best of our knowledge and by literature review, no practice has been initially applied by this method in Bangladesh coal mine areas at BCM. It would be favorable to convey at easy analysis with AHP-GA for posterior studies in regards to achieving further strong results. Due to adverse recent data availability, we cannot prescribe others hiding risk factors for BCM. Anyone can improve this gap by employing our method to apply on very recent data in the coal mine at BCM or similar mining areas to update the analysis for future contribution by AHP-GA method.

Immediately, a new coal mine safety plan of recommendation to the government will be an asset. In particular, our paper will be a great scope to other researchers and scholars for further contribution on judgement and planning strategy for the mining authority. Moreover, they can apply for the better result of judgment from multi-factor with respect to our novel approach on coal mine safety issues. However, the initial objectives of the study were to identify the risk factors that associated with Barapukuria coal mine common accidents. Secondly, application such kind of approached which can use to mitigate various factors connecting with accidents in mine. Thus, in this analysis, the integrated method of AHP and GA was shown to be capable of providing better results for evaluating risks factor. Future work recommendation, AHP-GA model modification need 
concerning proper GA parameter setting with AHP and the simulation approach by comparing different methods of MCDM linking with AHP.

\section{Approach to Coal Mine Safety}

The entire coal mine processing system is being investigated [25] and determine different hazard factors in coal mining. Coal Mine Safety assessment is not in favor of the authority at BCM yet. Many hiding factors are still unknown for lacking safeguard maintenance without a good working environment. It is required to look into the possibility of safety evaluation for the coal mine [24]. Approaching different methods and application is the prerequisite condition to evaluate accidents in the coal mine. This solution can also be obtained using other multicriterion decision-making methods including such VIKOR, GRA, ANP, and TOPSIS. There have some analyses using of genetic algorithm as a completion of work AHP method [4]. As a result, AHP is a more effective and preferable MCDM approach for solving problems with multiple criterion [5]. To perform the optimization process, GA is preserving points called individuals or specific factors, each of these is a possible solution to the problem of optimization from the population. This paper proposes one kind of viable method named as "AHP-GA". It can render a detailed assessment for objects or goals classified by different factors using the AHP-GA method [23].

\subsection{Identify Accidental Factors in Barapukuria Coal Mine (BCM)}

Hazardous situations and working behaviors occur in a slew of mishaps in underground coal mines; as a result, human deaths and injuries, property damage, production interruptions, among other things, are common phenomena in mine industry. The common causes of accidents in Barapukuria Coal Mining are roof fall, \& sides, land subsidence and house collapse, water inrush, mechanical hazard, spontaneous combustion, electrical hazard, poisonous gas emission, temperature \& humidity, and so on [2]. Coal mine accidents have various significant catastrophic consequences shown in table 1 and table $2[2, \mathbf{1 2}]$. For example, a local miner was killed for a roof-fall crash, and one of his leg amputated. In 2010, a major roof collapse happened in coal face 1108 due to a bump, resulting in the downfall of around 40 meters of belt gate pathway, the death of a local operative, and there were wounded 15 local and 3 Chinese employees [28]. In 2005, a severe water inrush in the BCM's central district caused coal production to halt for several days [27-28].

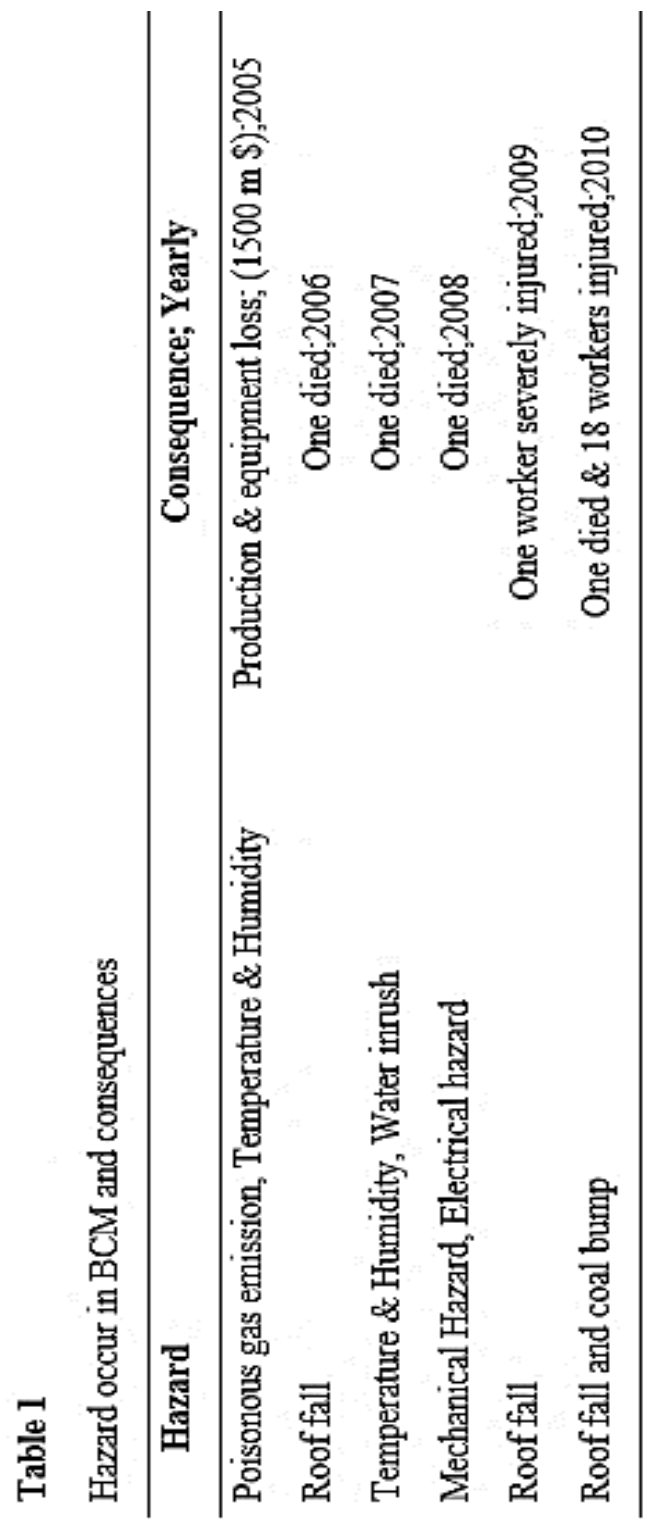

Trend of accidents in Barapukuria Coal Mine was analyzed by identifying many factors occurred as cause wise. Accident statistics (2002-2012) in BCM are listed in the table 2 according to causes of hazards and their years. The risk associated with these hazards are assessed to determine both on qualitatively and quantitatively, and if have other ways plan for mitigation hazards should be developed to be implemented. Furthermore, it allows for the appropriate implementation of the dangerous hazards, 
thus preventing any mishaps [1]. The aid of those given accident data and the AHP-GA approach suggested in this article, BCM data can play a dynamic role in hazard assessment. Therefore, many hazards and accidents were occurred like Roof fall \& sides, Subsidence, Temperature, humidity and so on.

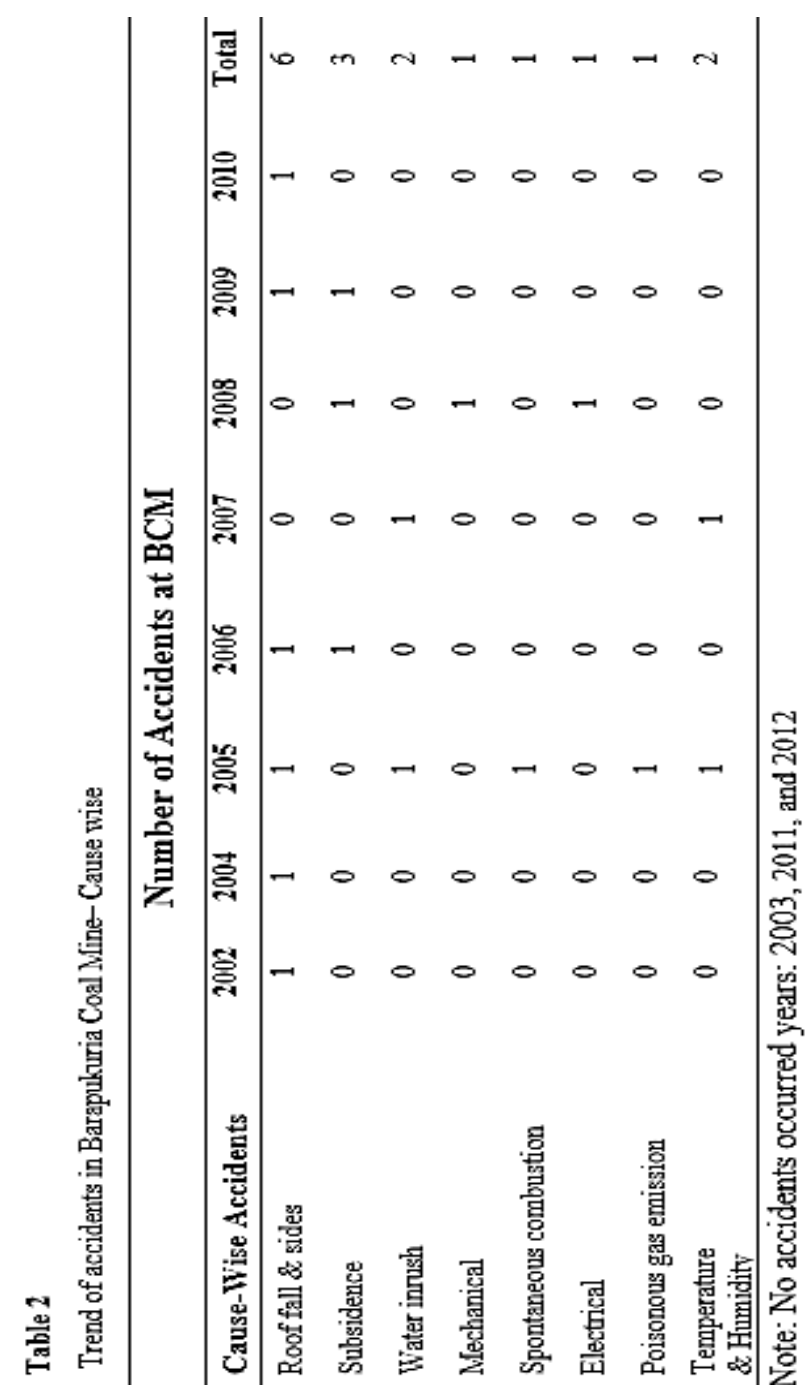

\section{Theoretical Analysis}

\subsection{Summary of Multi-Criteria Decision- Making (MCDM) Process}

Multi-Criteria Decision Making (MCDM) is a familiar Operations Research (OR) method for solving choice problems with multiple decision matrix and a small selection of options. Based on the difficulty issue, different MCDM techniques are used in technical decision analysis, like the weighted sum model (WSM), weighted product model (WPM), analytic hierarchy process (AHP), updated AHP, technique for order preference by similarity to ideal solution (TOPSIS), and elimination and choice translating reality (ELECTRE) [34]. Furthermore, the AHP weighting uncertainty analysis will add to the process of determining sustainability. From a statistical standpoint, the uncertainty analysis results will represent the sensitivity of the assessment results to the subjective criteria weight. Additionally, the genetic algorithm will evaluate the weights of variety factors (choice criteria) in the GA system.

\subsection{Problem for the Modelling and Method}

Hazardous factors being challenged in mining that should be identify with effective way to ensure occupational safety for a risk-free mining. To measure index weight value, the calculation result using AHP-GA can play a potential role for solving complex decision problem to measure risks of coal field including uniqueness character. For judgement, the organizer will spend a long time with decisionmakers (DMs) to construct the problem. Furthermore, applying various multi-criteria methods to the same problem which achieve different outcomes, rather than a specific or even similar output [8]. When allocating weights, AHP has the improvement of allowing a hierarchical system of requirement, allowing users to concentrate more on basic criteria and sub-criteria. This step is essential because of the diverse structure that could result in various final rankings [10]. The AHP is used with the weighted criterion and alternate weights. Then the weights of parameters used to determine the appropriateness of an alternative are extremely significant [6]. Furthermore, AHP will criticize if DMs would have unable to provide clear comparisons. When the number of parameters and alternatives is high, the problem becomes more challenging to apply modeling and decision-makers' methods. To tackle this problem, this paper focus to improve a novel and accurate utilizing method (AHP-GA), as well as to enhance the accuracy and efficiency of the process. On the other hand, the AHP-GA ranking method is validated by comparing its findings to those of other ordering methods published in the literature. Thus, the results of the AHP-GA model are very similar to those of other prioritization models [22]. 


\subsection{Theoretical Steps of Analytic Hierarchy Process (AHP)}

The most widely used MCDM model for solving difficulty problems is the analytic hierarchy process (AHP). It has advantages include straightforward theory, basic measurement methodology, ability to perform sensitivity analysis, versatility and use both qualitative and quantitative approaches [5]. AHP has an acquired theoretical system that divides nonstructural and dynamic circumstances into hierarchical components. In addition, starting with objective issue, key criterion, sub-criteria and ending with alternatives, AHP categorizes the problem into hierarchical levels [9]. Moreover, the relative importance of each variable is assigned a quantitative score, and the degree of intensity is calculated using these factors in the same way as variable weights were calculated. [29]. For the judgements, the functional structure aids to understand concisely: determining goals and making decisions depending on another standard. [22].

\section{Step 1.}

Primarily, the ultimate target of problem is located at the top of the scale, while the various decision options are at the end. The related characteristics of the result issue, such as criteria and sub-criteria, are found both the upper and lowest stages. The problem's complexity determines the number of levels in the hierarchy.

\section{Step 2.}

Secondly, relational data is created to compare the alternatives. This necessitates the formulation of pairwise comparison matrices of objects at each step of the analysis in relation to each individual at the next better elevation by the decision maker. Suppose a problem has $\mathrm{M}$ alternatives and $\mathrm{N}$ criteria. In that case, the decision-maker must create $\mathrm{N}$ judgment matrices of alternatives with $(\mathrm{M} \times \mathrm{M})$ order and one judgment matrices of criteria with $(\mathrm{N} \times \mathrm{N})$ order in AHP. Finally, the relative scores of the alternatives concerning each criterion can be used to construct the $(\mathrm{M} \times \mathrm{N})$ to get the decision matrix. AHP assigns priorities in a structured manner using a conceptual scale of real numbers from 1 to 15 and its mean values. The quantitative scale anticipated by Saaty [30-33] is applied when assimilating two parameters (or alternatives) concerning an attribute at a higher level. Table 3 depicts the scale.

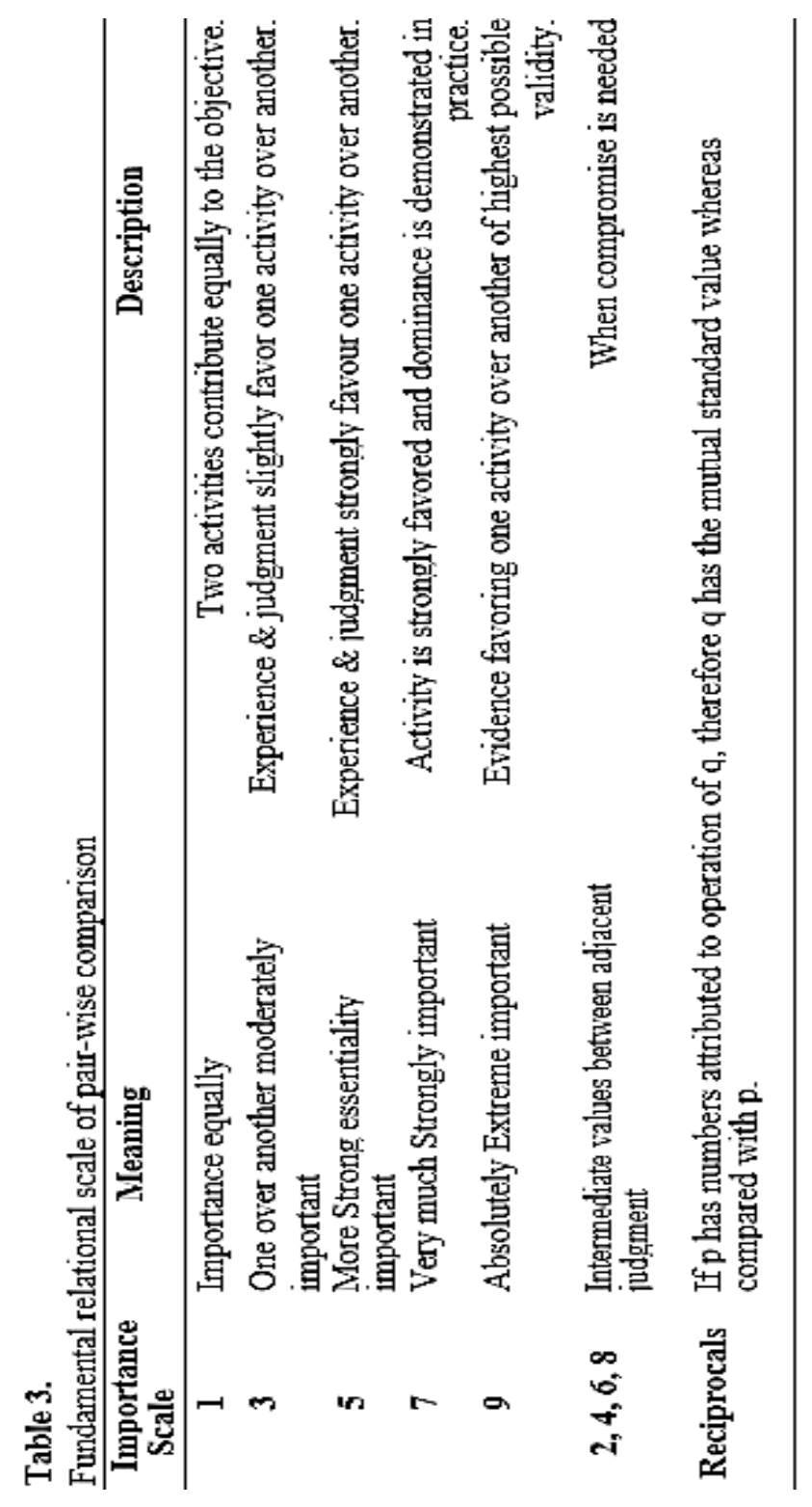

In the pair-wise comparison method, Table 3. shows Saaty's scale of priorities. Usually, the quantity of assessments is required $n(n-1) / 2$ in the upper-right triangle of the matrix, where $n$ is the size of matrix.

\section{Step 3.}

The relative value of different criteria about the problem's target and alternative scores for each of the criteria are calculated in this phase. The size of the comparison matrix $\left(\mathrm{C}_{1}\right)$ for $\mathrm{N}$ conditions will be $(\mathrm{N} \times$ 
$\mathrm{N})$ and the category of $\mathrm{C}_{\mathrm{ij}}$ will indicate the relative value of criterion $i$ with compare to the criterion $j$.

In the matrix, $C_{i j}=1$ if when $i=j$ and $C_{j i}$

$$
\begin{aligned}
& =\frac{1}{C_{i j}} . \\
C_{1} & =\left[\begin{array}{cccc}
1 & c_{12} & \ldots & c_{1 N} \\
c_{21} & 1 & \ldots & c_{2 N} \\
\ldots & \ldots & 1 & \ldots \\
c_{N 1} & c_{N 2} & \ldots & 1
\end{array}\right]
\end{aligned}
$$

The relative weight or importance of the $i^{\text {th }}$ criteria $\left(W_{i}\right)$ is determined by calculating the geometric mean (GM) of the $i^{\text {th }}$ row and then normalizing the geometric means of the rows of the above matrix. This can be represented as follows:

$$
G M_{i}=\left\{\prod_{j=1}^{N} c i j\right\}^{\frac{1}{N}} ; \text { and } W_{i}=\frac{G M_{i}}{\sum_{i=1}^{N} G M_{i}}
$$

Then matrix $C_{3}$ and $C_{4}$ are calculated such that

$$
\begin{gathered}
C_{3}=C_{1} \times C_{2} \text { and } C_{4}=\frac{C_{3}}{C_{2}}, \text { where } \\
C_{2}=\left[\begin{array}{llll}
W_{1} & W_{2} & \ldots & W_{N}
\end{array}\right]^{T}
\end{gathered}
$$

The average of matrix $\mathrm{C}_{4}$ is used to measure the principal eigen vector (maximum) of the original pair-wise comparison matrix $\left(\mathrm{C}_{1}\right)$, and similarly for others up to $\mathrm{C}_{6}$. Consistency Index (CI) and Consistency Ratio (CR) are determined from the following details to verify the consistency of pairwise comparison judgment:

Index of Consistency: This equation is used to assess the accuracy of responses that affect the truth's outcomes. The following equation can be used to calculate the consistency index eq. below:

$C I=\frac{\lambda \max _{-n}}{n-1}$

Where (n) denotes the size of the pair-wise comparison matrix and $\lambda_{\max }$ specifies the matrix's limit or primary eigenvalue. It points out that the matrix is accurate and therefore if $\lambda_{\max }=(\mathbf{n})$, and that we still need $\lambda_{\max }>(\mathbf{n})$; Whenever the matrix is a higher reliability one. As a result, the matrix is more stable, the similar the $\lambda_{\max }$ is to (n). Take into account the Consistency Ratio to determine whether (CI) is appropriate (CR).

The consistency ratio calculated by the eq. number 3 .

$$
C R=\frac{C I}{R I}
$$

As seen in the Table 4. the Random Index (RI) is dependent on the size of the matrix. According to Saaty, however, CR > 0.1 means that the decisions are at their most consistent, while CRs $>0.1$ (but not as much greater) must be agreed occasionally.

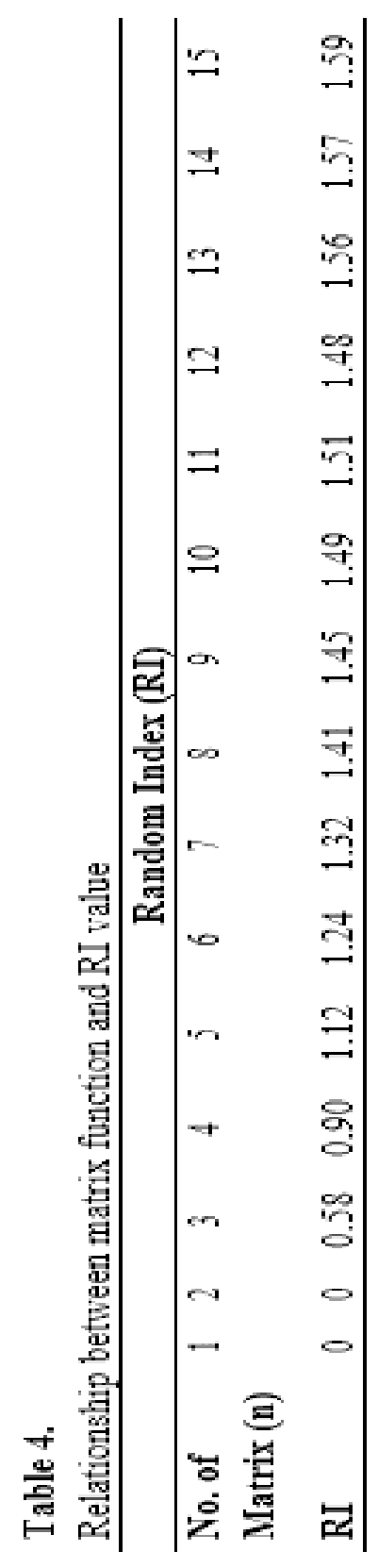


Criterion

\begin{tabular}{|c|c|c|c|c|c|}
\hline Alternatives & $\begin{array}{c}\boldsymbol{C}_{\boldsymbol{I}} \\
\left(\boldsymbol{W}_{\boldsymbol{I}}\right)\end{array}$ & $\begin{array}{c}\boldsymbol{C}_{2} \\
\left(\boldsymbol{W}_{2}\right)\end{array}$ & $\begin{array}{c}\boldsymbol{C}_{\boldsymbol{3}} \\
\left(\boldsymbol{W}_{3}\right)\end{array}$ & $\cdots$ & $\begin{array}{c}\boldsymbol{C}_{N} \\
\left(\boldsymbol{W}_{N}\right)\end{array}$ \\
\hline$A 1$ & a11 & a12 & a13 & $\ldots$ & a1N \\
\hline$A_{2}$ & a21 & $\mathrm{a} 22$ & a 23 & $\ldots$ & $\mathrm{a} 2 \mathrm{~N}$ \\
\hline A3 & $\mathrm{a} 31$ & $\mathrm{a} 32$ & a33 & $\ldots$ & $\mathrm{a} 3 \mathrm{~N}$ \\
\hline$\ldots$ & $\ldots$ & $\ldots$ & $\ldots$ & $\cdots$ & 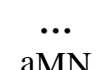 \\
\hline
\end{tabular}

Here,

$\sum_{i=1}^{M} a_{i j}=1$

\section{Step 4.}

Finally, the continuity formula is used to evaluate the final stage rank of all the options, taking into account the alternative grades $\left(a_{i j}\right)$ in each parameter and the weight of the accuracy value $\left(W_{j}\right)$. Where the eq. (4) below:

$A_{A H P}=\max \sum_{j=1}^{n} a_{i j} \cdot W_{j} ;$ for $i=123 \ldots M$

\subsection{Discussion theory of Genetic Algorithm (GA)}

One of the familiar evolutional algorithms, the genetic algorithm (GA), is a fast growing artificially intelligent tool which is applied for solving complicated and challenging problems in a variety of fields. To explore and prioritize specified statistical formulas and functions, it is mainly focused on encoded variables of corrective actions [4-5]. A string of binary numbers is commonly used to code individuals [34]. Using an optimization technique, distribution, replication, collectivism, crossing over children and electoral systems, GA is frequently used to figure out effective ways in a population [5]. For complicated and nuanced problems, there are a variety of ways to improve GA measurements [4]. Finally, GA focuses on areas of the search space where it is likely that better results will be obtained. GA is used to solve a variety of problems in a variety of fields, including improving weighting methods. [22]. The GA's basic operation mechanism is depicted in Figure 01, which contains three operators: search, enter, and transformation. Specific operator operation moves in a random sampling pattern, implying that the best possible solution migration rule in the group is random, and focused research is more efficient. Thus, it provides for solving complicated problems in a general system framework.

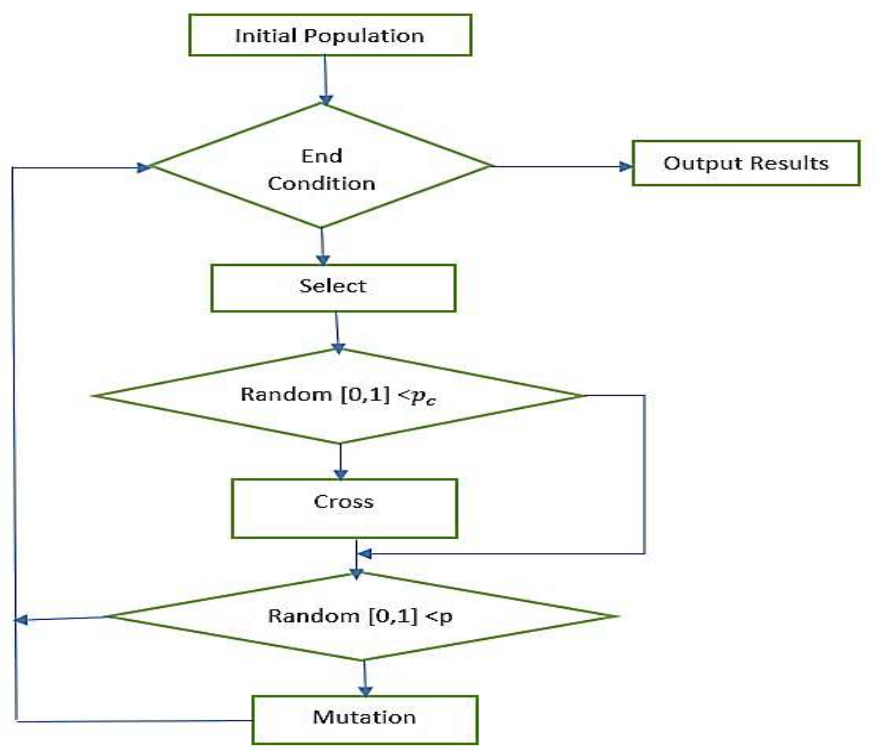

Fig.1. Processes of Genetic Algorithm Operation

\subsection{Case Study}

The calculation results of weight values are shown in table 05 , which are solved by root-mean-square and GA method. Two judgment matrixes represent as below:

$$
B_{1}=\left[\begin{array}{cccccc}
1 & 5 & 3 & 7 & 6 & 6 \\
1 / 5 & 1 & 1 / 3 & 5 & 3 & 3 \\
1 / 3 & 3 & 1 & 6 & 3 & 4 \\
1 / 7 & 1 / 5 & 1 / 6 & 1 & 1 / 3 & 1 / 4 \\
1 / 6 & 1 / 3 & 1 / 3 & 3 & 1 & 1 / 2 \\
1 / 6 & 1 / 3 & 1 / 4 & 4 & 2 & 1
\end{array}\right]
$$




$$
\text { and } \quad B_{2}=\left[\begin{array}{ccc}
1 & 3 & 5 \\
1 / 3 & 1 & 1 / 2 \\
1 / 5 & 2 & 1
\end{array}\right]
$$

The genetic algorithm results are more reliable compare to root-mean-square method, as shown in Table 5. When assessed using the root-mean-square rule, the evaluation matrix $\mathrm{B}_{2}$ cannot be passed the reliability check. The genetic algorithm's weight value may be sufficient to satisfy $\mathrm{B}_{2}$ 's consistency checks. As a consequence, when comparison to the root-mean-square process, GA can provide more precise weight values and accuracy tests.

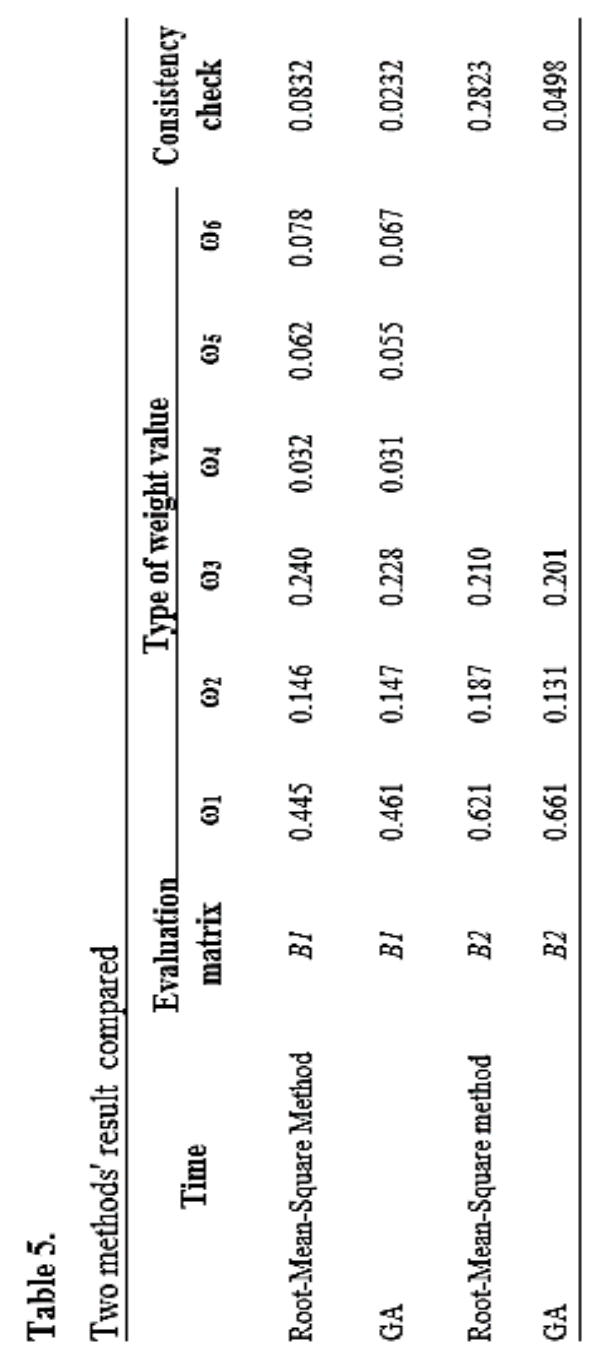

\section{BCM Accidents and Factors Analysis}

\subsection{Index Framework of BCM Safety}

In Fig. 2. Accidents in BCM is the target $Z$ layer. Roof fall, sides, subsidence, water inrush, electromechanical, temperature $\&$ humidity and poisonous gas emission were to generate the second decision layer of the index. There were 25 factors in the third decision layer. The factors index evaluation framework was presented below:

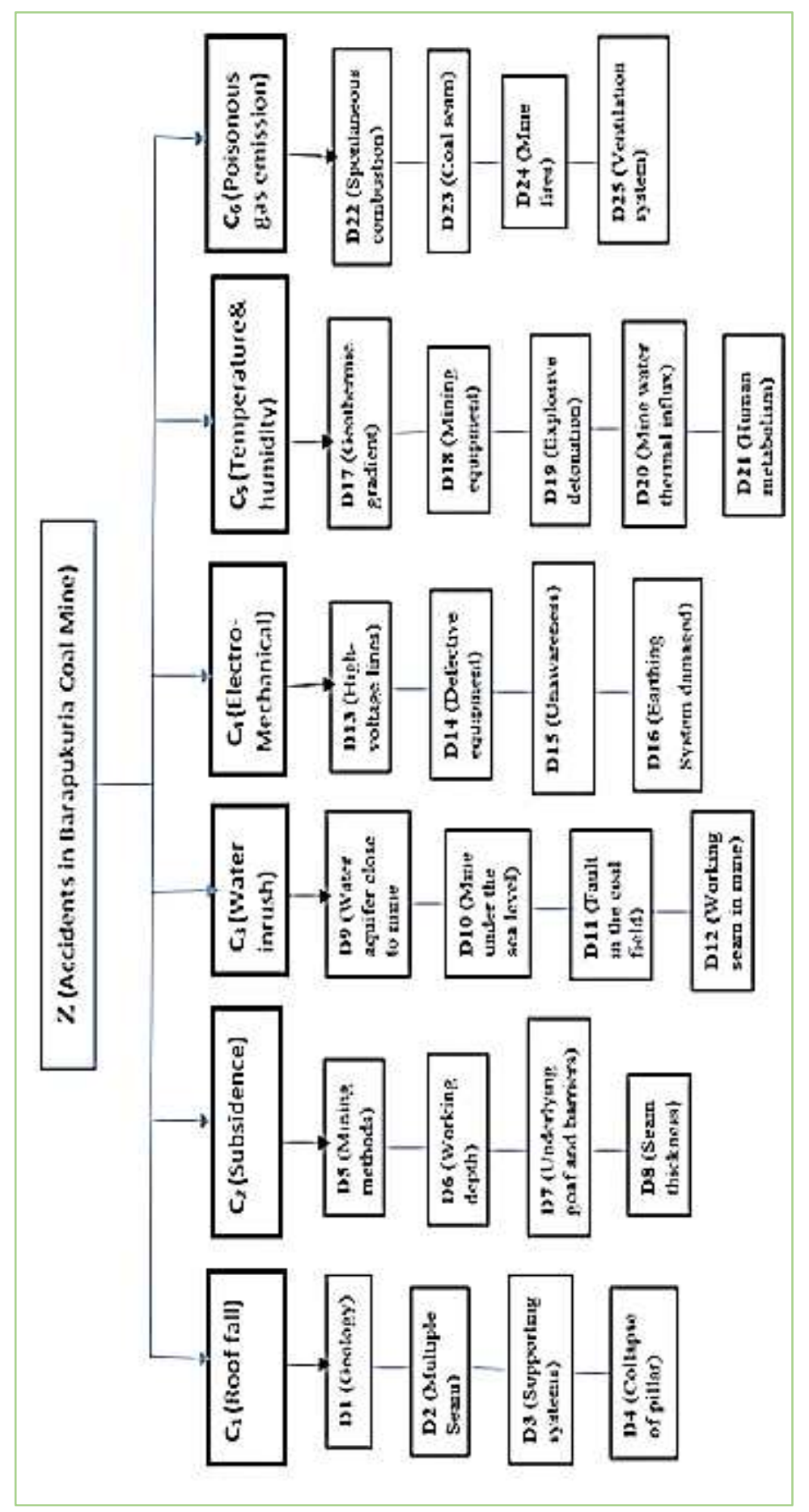


Fig. 2. Factors Index Evaluation Framework of Barapukuria Coal Mine Safety.

There were three levels to the factors list in our above fig. 2. The first element $\mathrm{Z}$ is our goal, after that decision layer is $\mathrm{C}$, and $\mathrm{C}$ contains $\left[\mathrm{C}_{1}, \mathrm{C}_{2}, \mathrm{C}_{3}, \mathrm{C}_{4}, \mathrm{C}_{5}, \mathrm{C}_{6}\right]$. The final layer is $\mathrm{D}$ as below:

$\mathbf{C}_{1}=\left\{D_{1}, D_{2}, D_{3}, D_{4}\right\}, \mathbf{C}_{2}=\left\{D_{5}, D_{6}, D_{7}, D_{8}\right\}, \mathbf{C}_{3}=$ $\left\{D_{9}, D_{10}, D_{11}, D_{12}\right\}, C_{4}=\left\{D_{13}, D_{14}, D_{15}, D_{16}\right\}$, $\mathbf{C}_{5}=\left\{D_{17}, D_{18}, D_{19}, D_{20}, D_{21}\right\}$, and $\mathbf{C}_{6}=\left\{D_{22}\right.$, $\left.\mathrm{D}_{23}, \mathrm{D}_{24}, \mathrm{D}_{25}\right\}$.

However, the remark set was divided into six phases, $\mathrm{X}=\{$ (worse, worst), (moderate, general), (best, better)\} Fig. 3. We cannot have assumed which decision levels of the factors were tending to risky or safe. The calculation was completed by the Microsoft excel and Matlab software to get better judgement from decision matrix.

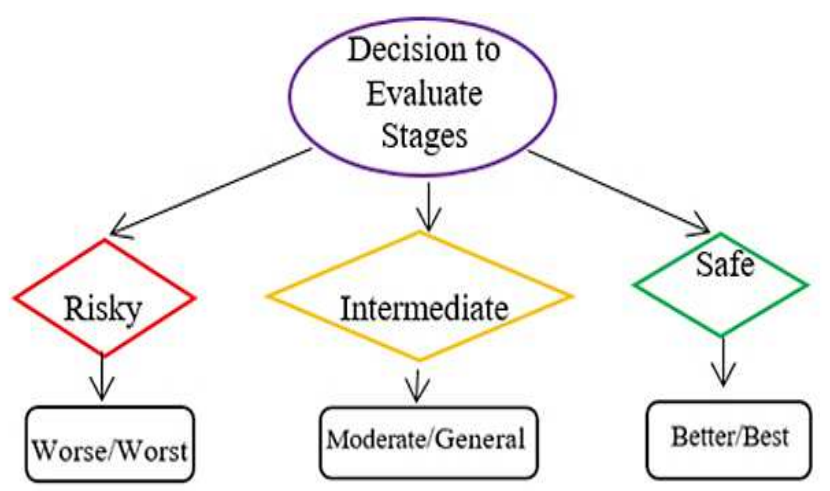

Fig. 3. Stages of Decision Assessment for BCM

\subsection{Confirmation of Decision Matrix}

The decision layer's assessment matrix can be accomplished by determining the priority degrees, as shown below:

$$
Z=\left[\begin{array}{cccccc}
1 & 2 & 3 & 5 & 3 & 4 \\
1 / 2 & 1 & 2 & 4 & 2 & 3 \\
1 / 3 & 1 / 2 & 1 & 2 & 1 / 2 & 1 / 2 \\
1 / 5 & 1 / 4 & 1 / 2 & 1 & 1 / 4 & 1 / 2 \\
1 / 3 & 1 / 2 & 2 & 4 & 1 & 2 \\
1 / 4 & 1 / 3 & 2 & 3 & 1 / 2 & 1
\end{array}\right]
$$

$$
C_{1}=\left[\begin{array}{cccc}
1 & 3 & 4 & 2 \\
1 / 3 & 1 & 2 & 1 / 2 \\
1 / 4 & 1 / 2 & 1 & 2 \\
1 / 2 & 2 & 1 / 2 & 1
\end{array}\right]
$$$$
C_{2}=\left[\begin{array}{cccc}
1 & 2 & 3 & 2 \\
1 / 2 & 1 & 1 & 1 / 2 \\
1 / 3 & 1 & 1 & 3 \\
1 / 2 & 2 & 1 / 3 & 1
\end{array}\right],
$$$$
C_{3}=\left[\begin{array}{cccc}
1 & 1 / 2 & 2 & 3 \\
2 & 1 & 3 & 4 \\
1 / 2 & 1 / 3 & 1 & 2 \\
1 / 3 & 1 / 4 & 1 / 2 & 1
\end{array}\right]
$$

$$
C_{4}=\left[\begin{array}{cccc}
1 & 2 & 3 & 5 \\
1 / 2 & 1 & 1 & 2 \\
1 / 3 & 1 & 1 & 1 / 2 \\
1 / 5 & 1 / 2 & 2 & 1
\end{array}\right],
$$

$$
C_{5}=\left[\begin{array}{ccccc}
1 & 2 & 5 & 3 & 4 \\
1 / 2 & 1 & 2 & 1 & 3 \\
1 / 5 & 1 / 2 & 1 & 2 & 2 \\
1 / 3 & 1 & 1 / 2 & 1 & 1 \\
1 / 4 & 1 / 2 & 1 / 2 & 1 & 1
\end{array}\right]
$$

$$
C_{6}=\left[\begin{array}{cccc}
1 & 2 & 3 & 4 \\
1 / 2 & 1 & 2 & 3 \\
1 / 3 & 1 / 2 & 1 & 2 \\
1 / 4 & 1 / 3 & 1 / 2 & 1
\end{array}\right]
$$

\subsection{Judgment based Check on weight value and the accuracy}

Table 6. shows the weight value and accuracy check results using the GA process. 


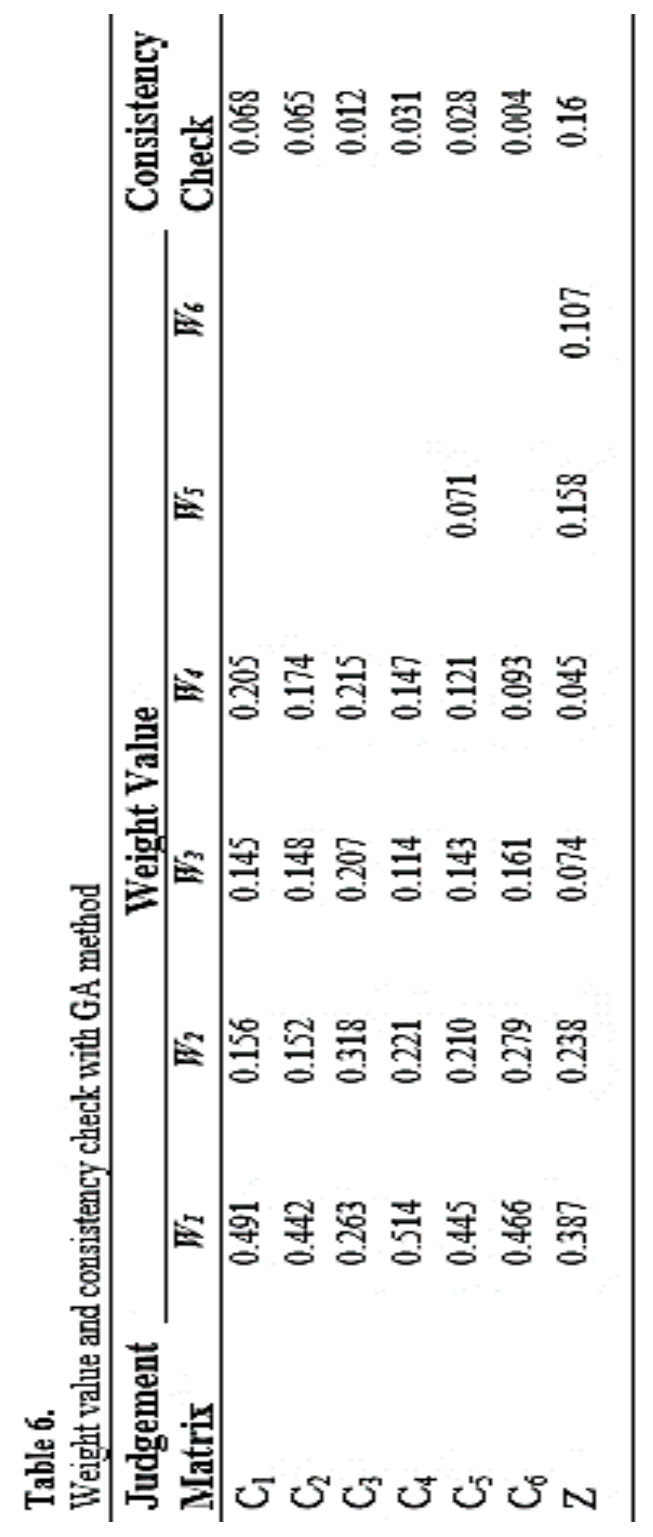

\section{Result and Discussion}

Assessment system of safety factors has abundant calculation indexes in coal mines. Separate construction atmosphere is caused by the different levels of accidents. Next to, hazard factors sorting is very complex for industrial risk assessment and applied step by step for the risk assessment process. Our analysis advantage is drawn that the security performance of coal mine workers depends on dominance existing factors. It is clearly depicting that major mine information of BCM calamities necessary to reserve progressively. By calculation, the consolidated case study for weights value and consistency compared with other existing factors was significant evaluation through our proposed AHP-GA method. The ultimate assessment of outcome factors accidents was,

$\mathrm{Z}=\left[\begin{array}{llllll}0.387 & 0.238 & 0.074 & 0.045 & 0.158 & 0.107\end{array}\right]$. It is an observed finding from our study that preservation of risk identification of BCM database systems is necessary to analyze and for good decisions. According to the maximum affiliation, the proposed coal mine has a "general" level of safety. We found that the "worst" level hazard was roof fall $\&$ sides, and "worse", level subsidence from weight value and consistency check results with GA method. However, electro-mechanical and temperature \& humidity were "general" and "moderate" respectively. Moreover, water inrush was "better" in condition and last one poisonous gas emission that was danger free in Barapukuria Coal Mine. Thus, this method based on multi-ordered evaluation approach is built and verified successfully at BCM.

\section{Conclusion}

Methodical safety management is important in industrial processes to avoid possible accidents whereas this paper approach will be able to solve the decision making problem of mining safety methods. MCDM is a renowned estimation procedure of coal mine safety measures but the standard weight result is not accurate. The key intention of this paper was to provide a decision support to the mining authority by selecting risk factors for the best safety environment. The AHP process is applied for perfect decision while dealing with unpredictable events and different assessments on various factors. Then GA has been used to solve a range of problems, including developing balance techniques in various fields. Furthermore, case studies result of GA has satisfied accuracy that help to confirm taking decisions for identifying risks in Barapukuria Coal Mine. Combining AHP-GA calculation showed the proposed method has ability to evaluate safety systems in the coal mine at BCM. Present study shows that BCM is maintaining an intermediate level of safety. Thus, the proposed AHP-GA method indicates roof fall \& sides, and subsidence accidents are more dangerous than other factors in the coal mine at Barapukuria. The results of the AHP-GA pathway were to acquire a good guidance of appropriate decision for identifying the dangerous factors that were validated by applying the weight aggregation in a different year also. 


\section{Acknowledgments}

We thank Barapukuria Coal Mining Company Limited (BCML) to provide valued information and previous published report. Authors thank the editors and anonymous reviewers for their insightful comments and suggestions.

\section{Funding}

This research paper work was not funded by a specific project grant, but partially from CSC and Central South University's scholarship sources of authors.

\section{Conflicts of Interest}

All authors have read and agreed to the published final version of the manuscript. The authors declared no conflict of interest.

\section{References}

Singh, M., Pant, M. (2021). A review of selected weighing methods in MCDM with a case study. Int J Syst Assur Eng Manag 12, (126-144) https://doi.org/10.1007/s13198-020-01033-3.

Habib, M.A., Basuki, T., Miyashita, S. et al. (2019). Assessment of natural radioactivity in coals and coal combustion residues from a coal-based thermoelectric plant in Bangladesh: implications for radiological health hazards. Environ Monit Assess 191(91), https://doi.org/10.1007/s10661-0187160

Bajić, S., Bajić, D., Gluščević, B., \& Ristić Vakanjac, V. (2020). Application of Fuzzy Analytic Hierarchy Process to Underground Mining Method Selection. Symmetry, 12(2), 192. doi:10.3390/sym12020192

İnce, M., Yiğit, T., \& Hakan Işik, A. (2020). A novel hybrid fuzzy AHP-GA method for test sheet question selection. International Journal of Information Technology \& Decision Making, 19(02), 629-647.

Li XM, Wang ZH, Zhang JW. Stability of roof structure and its control in steeply inclined coal seams. Int J Mining Sci Technol 2017;27(2):359-64

Putri, M. A., Aknuranda, I., \& Mahmudy, W. F. (2017). Development of a Conceptual Framework to
Determine Improvement of IT Governance using COBIT 5 and AHP-GA. Journal of Telecommunication, Electronic and Computer Engineering (JTEC), 9(2-8), 43-49.

Miller III, J. R. (1966). The assessment of worth is a systematic procedure and a systematic procedure and experimental validation (Doctoral dissertation, Massachusetts Institute of Technology).

Rahimi, S., Roodposhti, M. S., \& Abbaspour, R. A. (2014). Using combined AHP-genetic algorithm in artificial groundwater recharge site selection of Gareh Bygone Plain, Iran. Environmental earth sciences, 72(6), 1979-1992.

Hman, S., \& Jarndal, A. (2017, April). A two stage green supplier selection and order allocation using AHP and multi-objective genetic algorithm optimization. In 2017, 7th International Conference on Modeling, Simulation, and Applied Optimization (ICMSAO) (pp. 1-6). IEEE.

Peter Nes., L. Sipeki, Tulay Flamand, Alexandra M. Newman. (2021). Optimizing underground mine design with method-dependent precedences. IISE Transactions 53:6, pages 643-656.

Soba, M., Ersoy, Y., Tarakcioğlu Altınay, A., Erkan, B., \& Şik, E. (2020). Application of Multiple Criteria Decision-Making Methods in Assignment Place Selection. Mathematical Problems in Engineering, 2020.

BCMCL (2011). Annual Report 2010-2011, Barapukuria Coal Mining Company Limited, Chouhati, Parbatipur, Dinajpur, 92p.

Shi, L., Qiu, M., Teng, C. et al. (2020). Risk assessment of water inrush to coal seams from underlying aquifer by an innovative combination of the TFN-AHP \& TOPSIS techniques. Arab J. Geosci 13, 600. https://doi.org/10.1007/s12517-02005588-0

Javadi, M., Saeedi, G., \& Shahriar, K. (2017). Developing a new probabilistic approach for risk analysis, application in underground coal mining. Journal of Failure Analysis and Prevention, 17(5), 989-1010. 
Yang, W., Xia, X., Pan, B., Gu, C., \& Yue, J. (2016). The fuzzy comprehensive evaluation of water and sand inrush risk during underground mining. Journal of Intelligent \& Fuzzy Systems, 30(4), 2289-2295.

Gang K., Yan. Lu, Yi P., \& Yong S., (2020). EVALUATION OF CLASSIFICATION ALGORITHMS USING MCDM AND RANK CORRELATION. Int. J. Inf. Tech. \& Dec. Making, Vol. 11, No. 01, pp. 197-225 (2012), https://doi.org/10.1142/S0219622012500095

Chong, T., Yi, S., \& Heng, C. (2017). Application of set pair analysis method on the occupational hazard of coal mining. Safety Science, 92, 10-16.

Zhang, J., He, P., Xiao, J., \& Xu, F. (2018). Risk assessment model of expansive soil slope stability based on Fuzzy-AHP method and its engineering application. Geomatics, Natural Hazards, and Risk, 9(1), 389-402.

Qiao, G. T., Zhu, Y. N., \& He, G. (2016). Evaluation of coal miners' safety behavior based on AHP-GRAP and MATLAB. Journal of Computational Methods in Sciences and Engineering, 16(1), 49-55.

Ionica, A., \& Leba, M. (2015). Human action quality evaluation based on fuzzy logic with application in underground coal mining. Work, 51(3), 611-620.

Cinar, U., \& Cebi, S. (2020). A hybrid risk assessment method for the mining sector based on QFD, fuzzy inference system, and AHP. Journal of Intelligent \& Fuzzy Systems, (Preprint), 1-12.

Aly, M. F., El-hameed, H. M. A., \& Abd, M. (2013). Integrating AHP and genetic algorithm model adopted for personal selection. International Journal of Engineering Trends and Technology (IJETT), 6(5).

Dong, S. H., Zhao, Y. K., \& Li, M. (2013). Improvement of Analytic Hierarchy Process and Its Application for Coal Mine Safety Assessment. In Applied Mechanics and Materials (Vol. 368, pp. 1979-1984). Trans Tech Publications Ltd.

Yajing, L., Shanjun, M., Jiming, Y., \& Ruidong, H. (2007). Comprehensive Safety Evaluation of Coal
Mine Based on Analytic Hierarchy Process. Mining Research and Development, 2, 83-86.

25. Ruan, Z., Li, C., Wu, A. et al. (2019). A New Risk Assessment Model for Underground Mine Water Inrush Based on AHP and D-S Evidence Theory. Mine Water Environ 38, 488-496 https://doi.org/10.1007/s10230-018-00575-0

26. Islam, M.R; Islam, M.S. (2005). Water Inrush Hazard in Barapukuria Coal Mine, Bangladesh. Bangladesh Journal of Geology, 24, 1-17.

27. Imam, B. (2013). Energy Resources of Bangladesh, second edition, University Grant Commission, Bangladesh, pp. 324.

28. H.S. Wang, Z.H. Che, Chienwen, Wu. (2010). Using analytic hierarchy process and particle swarm optimization algorithm for evaluating product plans. Expert Systems with Applications, pp. 1023-1034.

Saaty, T. L. (1986). The axiomatic foundation of the analytic hierarchy process. Management Science, 32(7), 841-855.

Saaty, T. L. (1990). How to make a decision: the analytic hierarchy process, European journal of operational research, 48(1), 9-26.

Saaty, T. L. (1983). Priority setting in complex problems. IEEE Transactions on Engineering Management, (3), 140-155.

Saaty, T. L. (1994). Highlights and critical points in the theory and application of the analytic hierarchy process. European journal of operational research, 74(3), 426-447.

Holland, J. H. (1973). Genetic algorithms and the optimal allocation of trials. SIAM journal on computing, 2(2), 88-105.

Banwet, D. K., \& Majumdar, A. (2014). Comparative analysis of AHP-TOPSIS and GA-TOPSIS methods for selection of raw materials in textile industries. In Proceedings of the International Conference on Industrial Engineering and Operations Management (pp. 2071-2080). 


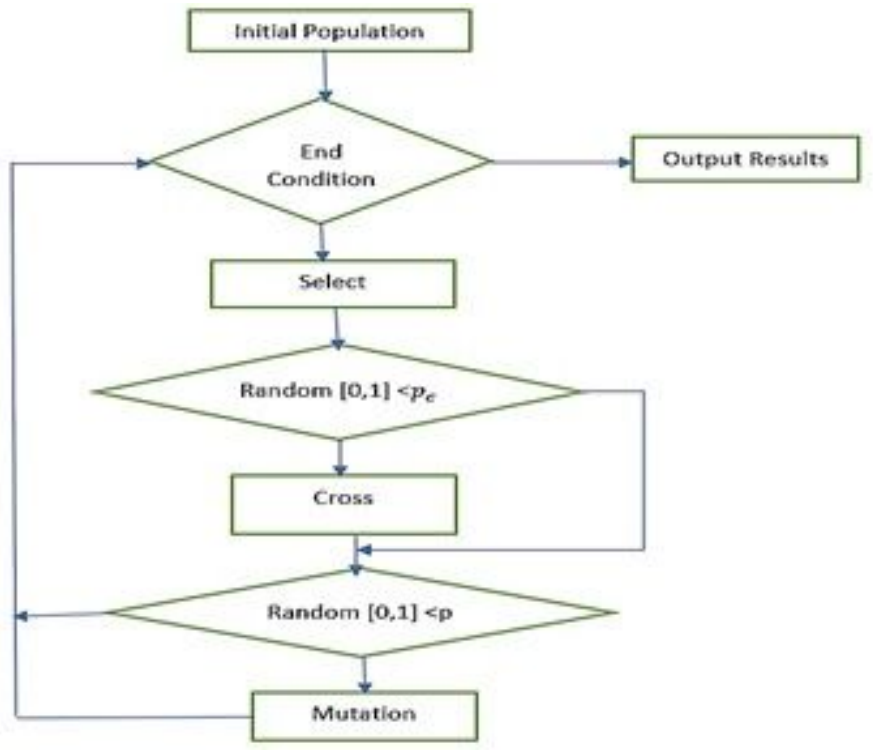

Figure 1

Processes of Genetic Algorithm Operation

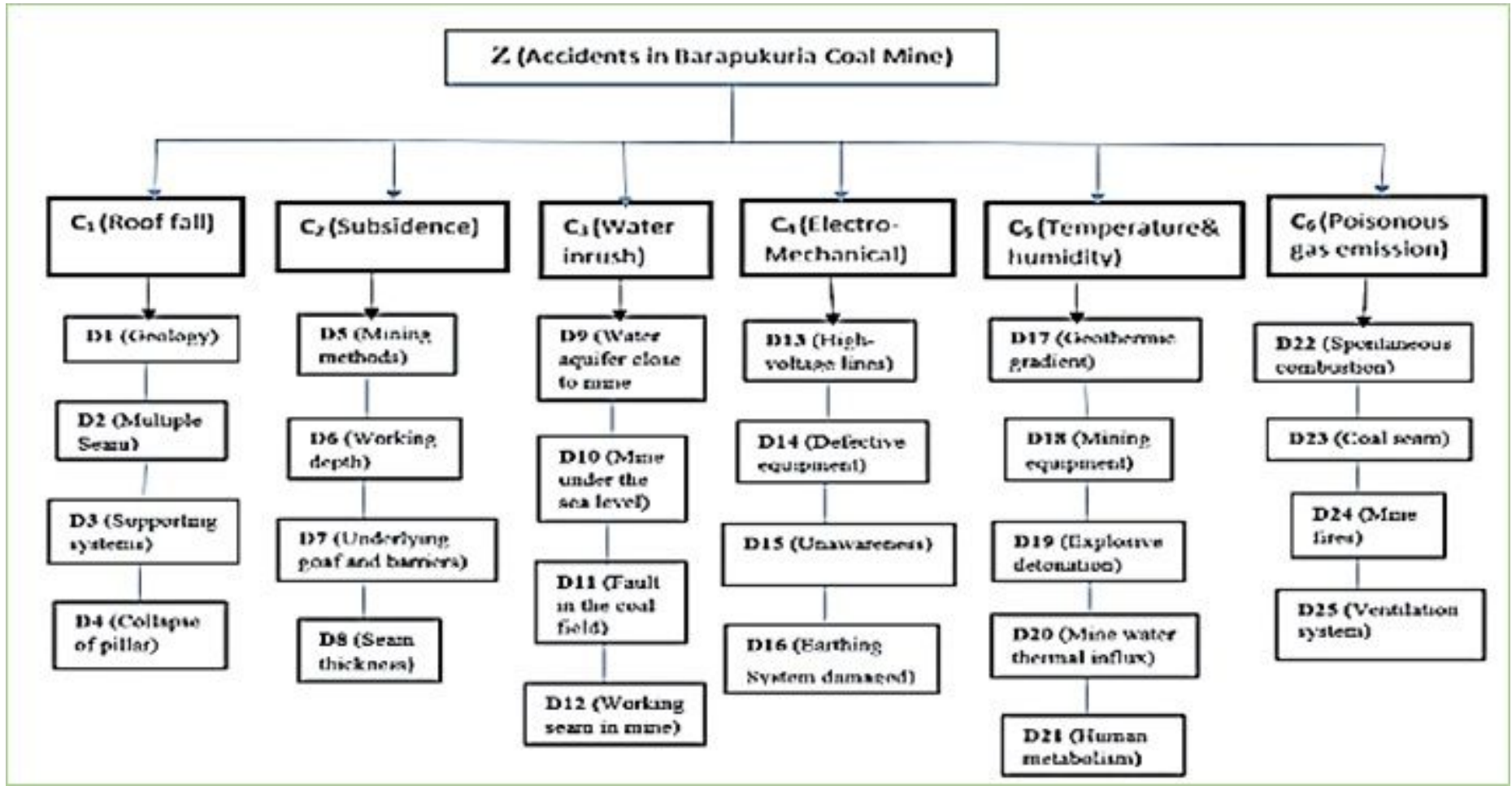

Figure 2

Factors Index Evaluation Framework of Barapukuria Coal Mine Safety. 


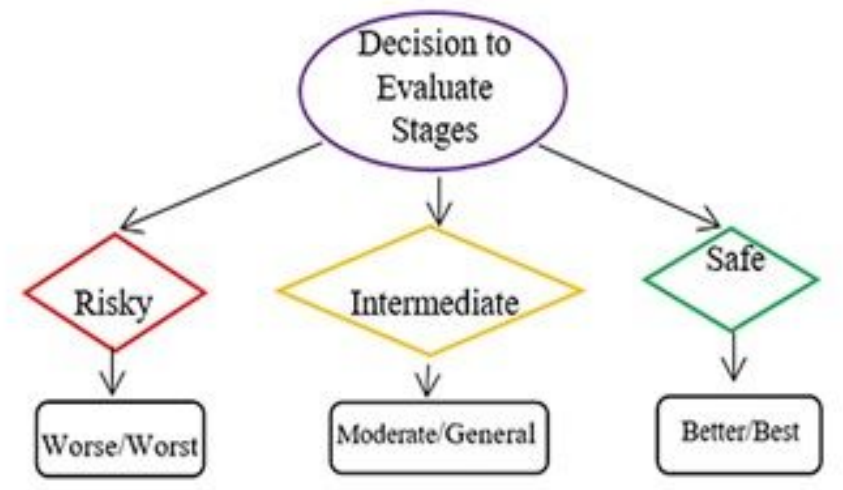

Figure 3

Stages of Decision Assessment for BCM 